Abstracta Iranica Abstracta Iranica

Revue bibliographique pour le domaine irano-aryen

Volume 32-33 | 2013

Comptes rendus des publications de 2009-2010

\title{
Maryse Blet-Lemarquand. La question récurrente de la raison d'être de 'pd sur le monnayage de Khusrō II (590-628) : étude préliminaire
}

Nikolaus Schindel

\section{(2) OpenEdition \\ 1 Journals}

\section{Electronic version}

URL: http://journals.openedition.org/abstractairanica/40463

DOI: $10.4000 /$ abstractairanica.40463

ISSN: 1961-960X

Publisher:

CNRS (UMR 7528 Mondes iraniens et indiens), Éditions de l'IFRI

Printed version

Date of publication: 1 December 2013

ISSN: 0240-8910

Electronic reference

Nikolaus Schindel, « Maryse Blet-Lemarquand. La question récurrente de la raison d'être de 'pd sur le monnayage de Khusrō II (590-628) : étude préliminaire », Abstracta Iranica [Online], Volume 32-33 | 2013, document 142, Online since 01 July 2016, connection on 05 October 2020. URL : http:// journals.openedition.org/abstractairanica/40463; DOI : https://doi.org/10.4000/abstractairanica 40463

This text was automatically generated on 5 October 2020 .

Tous droits réservés 


\title{
Maryse Blet-Lemarquand. La question récurrente de la raison d'être de 'pd sur le monnayage de Khusrō II (590-628) : étude préliminaire
}

\author{
Nikolaus Schindel
}

\section{REFERENCES}

Maryse Blet-Lemarquand. « La question récurrente de la raison d'être de 'pd sur le monnayage de Khusrō II (590-628) : étude préliminaire ». Res Orientales XVIII, Sources pour l'histoire et la géographie du monde iranien (224-710). Bures-sur-Yvette / Leuven, GECMO / Peeters Press, 2009, p. 41-58.

1 The author analyzes drachmas of the Sasanian king Khusro II (590-628) that bear the Pehlevi words ' $p d$ (conventionally read as "wonderful") in the obverse margin. Since the majority of the ' $p d$ coins have a silver content of about $99 \%$ compared with $95 \%$ of the coins without ' $p d$, the word was probably placed there by the minting authority to denote pure silver drachmas.

\section{AUTHORS}

NIKOLAUS SCHINDEL

Österreichische Akademie der Wissenschaften, Wien 